\title{
AMÉRICA, EPISTEMOLOGÍAS DEL SUR. ¿METANOIA O IMPENITENCIA ARQUITECTÓNICA?
}

\author{
Editores: Manoel Rodrigues Alves \& Carlos Tapia \\ IAU São Paulo \& ETSA Sevilla \\ https://dx.doi.org/10.12795/astragalo.2018.i25.01
}

Timeo Danaos et dona ferentes.

"Desconfío de los dánaos incluso cuando traen regalos". Con esta afamada frase de Laocoonte, aplicada a la arquitectura contemporánea, podría afirmarse que la resistencia contra la Modernidad instalada es comparable a la desigual lucha entre dioses y aquellos gigantes engendrados al efecto como sus contrapartes. Si el friso del altar de Pérgamo es conocido como un canto a la resistencia contra la tiranía divina, e inspira al Laocoonte -el de Winckelmann, el de Lessing- y fija la atención en la dinamicidad de los dos bandos contendientes, es necesario precisar que existe un tercer actor, un caballo con un equívoco acechante en su interior. Tal confusión proviene de garantizar una globalización mediante la concesión de licencias de reconocimiento secundario, supeditado a lo que Ortega llamaría el terruño, o Frampton, hace casi cuatro décadas, Regionalismo Crítico.
Al paternalismo eurocéntrico por conceder carta de naturaleza a los outsiders que bien valen una misa, no le falta solicitudes de adopción, ha de reconocerse, pero ese escrutinio habrá de esperar una mejor ocasión.

El troyano Laocoonte resiste contra los invasores griegos con la existencia de un tercer elemento aparentemente ajeno, pero que sólo simboliza la prevalencia del más fuerte: el que se cree vencedor, o el que finalmente vence. La concesión del tercero incluido no es más que la aquiescencia necesaria para que la reacción sea controlada y, desde luego, no la oportunidad de una lógica polivalente, como sabemos desde Aristóteles y su evolución en una de las leyes básicas de la filosofía.

En la conmemoración del Mayo del 68, este 2018 se presentan en todo el mundo libros, congresos y revistas que realizan revisiones de 
la noción de resistencia y del papel que los arquitectos y sus obras podrían tener hoy.

Por poner un ejemplo, en términos historiográficos, Jean Louis Cohen ni siquiera se molesta en colocar en la historia el término, ése que llamaríamos la dádiva Regionalismo Crítico, sino que lo coloca en el marco de una internacionalización de arquitectos y arquitecturas "con denominación de origen". Sin embargo, en paralelo, surgen actualmente renovados intereses en la academia y en los medios de producción arquitectónicos por insuflar vida ampliada a esa concesión condescendiente.

La pregunta que este número de Astrágalo quiere responder no es la vacuidad de la lucha en un mundo con pocas alternativas, sino el papel que le correspondería a la arquitectura como resistencia, desde una perspectiva histórica y de prácticas proyectuales y cívicas, y si es posible mantenerla hoy. En un contexto de espacialidades de la instantaneidad y de continua transformación (mutación) de tejidos y morfologías urbanas, de alteración de estructura jerárquica de un territorio urbano multiescalar-debemos dejarlo claro-, muchos de los mecanismos y acciones de resistencia ya se han reabsorbido y no se les presume utilidad alguna.

En continuidad con el número 24, Estéticas de la globalización: Apogeo y resistencias, el comité editorial quiere encontrar una voz sin anuencia que pueda acondicionar un hacer, frente a esa lógica mundializada en la particularidad "regional-global" de América Latina.

Si admitimos la precisión argumentativa del desaparecido arquitecto Lebbeus Woods, resistir no connota negativamente como "descartar" o "rechazar". Más al contrario, implica una lucha medida que es más táctica que estratégica, según sus propias palabras. Para nosotros, se trata de afrontar (hacer frente) a la situación y dilucidarla en el contexto contemporáneo.

Así pues, como precautoria a la hipótesis propuesta a este monográfico, se debe hacer notar que comenzar con una mención a la Grecia clásica es ya una contradicción en nuestros supuestos, conjurada felizmente por los artículos incluidos en este número. Son voces que evitan tanto cargarse de razón por el mero hecho de hablar desde dentro, como soslayan la imposición de visiones por partir de posicionamientos exógenos legitimados por los procesos de opresión intelectual. Este colonialismo cultural es lo que, para una demanda de justicia espacial, Boaventura de Sousa Santos quiere exorcizar mediante la expresión Epistemologías del Sur, comenzando por una justicia cognitiva que debe ser global. Sólo por esa razón táctica se hace uso del caballo-regalo griego, como una oportunidad tercera de reubicación de los conocimientos globales. En la misma medida, como es sabido, conceptualizar y nombrar con la acepción "América Latina" es otro equívoco según los principios básicos que estamos deslindando, ya que responde al proyecto imperial francés ejemplificado por Maximiliano en México y divulgado en, según Gabriel Restrepo, uno de los peores poemas de toda la historia, "Las dos Américas", publicado en Francia en 1856. Para el autor colombiano, sería mejor usar "América Ladina", como expresión de transculturalidad establecida por los indios diseminados al sur del río Bravo con un español del siglo XIII como nexo idiomático y, como sabemos por Eduardo Galeano, sería el garante de una posibilidad táctica frente a las "venas abiertas de América Latina".

Por su parte, habiendo sido una vez modelo de inspiración regional, la arquitectura moderna brasileña, en la búsqueda de una expre- 
sión nacional legítima a partir de una expresión cultural autóctona, descubrió nuevas posibilidades en la construcción de una identidad nacional. Promotora de una expresión nativa, más que contrariar, subvirtió una de las utopías del estilo internacional y de las vanguardias constructivas: el ideal de la a-territorialidad y de la a-historicidad. Pero, ¿dónde se encuentra ese ideario?, ¿cuánto de él permanece?

Añadido a ello, un autor como Adrián Gorelik propone un análisis histórico de la categoría "ciudad latinoamericana" como construcción cultural, entendiendo que, entre la segunda posguerra y los años 70, la idea de "ciudad latinoamericana", en lugares y contextos distintos, funcionó como una categoría del pensamiento social, pero también como una figura del imaginario intelectual y político. Sin embargo, el análisis de la conformación de la ciudad latinoamericana desde los fines del siglo XX posibilita la identificación de signos de continuidad vinculados a procesos de una eterna modernidad, expresión, como apunta Quijano, de una "colonialidad del poder" con relación a la matriz colonial de las ciudades y, en particular, en la América Latina hispana.

Hoy, podría decirse que, en la mayor parte de las ciudades latinoamericanas, cuando hay interés en asumir del modelo de Medellín, lo que se trasluce son las políticas y los planes urbanos locales en procesos de recualificación asociados a un paradigma de ciudad representada (escenográfica), que aparentemente buscan retomar la dimensión cultural en el sentido inclusivo y comunitario en territorios caracterizados por su vulnerabilidad social. Pero, ¿en qué medida la propuesta y el paradigma de Medellín no serían sino una vanguardista estrategia de gestión entre el Estado y los secto- res privados en la promoción de un urbanismo adornado como "urbanismo social"? Y si atendemos a los efectos de "tensión / negociación" que Bourdieu definía en los años 90, ¿no tendría que desnaturalizarse ya esa visión negociada y positivada de tal urbanismo social, despolitizada y ausente de conflicto, como estrategia reparadora del espacio urbano de convivencia, esto es, de la ciudad?

Atentos al argumento de Gorelik, por cuanto ese entendimiento pueda ofrecer posibilidades interesantes para el actual momento latinoamericano, nos preguntamos, ¿cuál es la realidad urbana y cultural contemporánea que cabría con claridad en esta categoría? ¿cuál es su arquitectura? ¿a qué pensamiento político e intelectual responde? Y, ¿en qué medida la ciudad latinoamericana se presenta como un mecanismo de bienestar e inclusión, alertando del absurdo de definir esa realidad por medio de un ideal de representación de un conjunto de características inherentes a una cierta categoría de ciudad, a una cierta categoría de lo urbano?, ¿se detecta un cambio de sensibilidad en esta parte del continente como para aprender de ello?

Etimológicamente, la palabra metanoia se origina en el griego metanoein, formado a partir de la unión de metá, que significa “después"; y voṽ , que significa "pensamiento" o "intelecto". Así, la interpretación literal del término significa la acción de cambiar el propio pensamiento, de no más seguir o creer en algo, en cierta cosa, para vivir un nuevo modo de ver un determinado contexto. Sloterdijk recuerda que, en origen, el término metanoia significaba un cambio de mentalidad, o más básicamente, un mero cambio de opinión. Sin embargo, al ser empleado por Bourdieu o Foucault, llega a connotar un tipo de comprensión superior sos- 
tenida por un observador entrenado que lleva a una aprobación de los hechos estudiados. En el momento latino-americano, cuál es la metanoia posible, o sea, ¿cuál es el cambio que se hace necesario al pensamiento y al carácter latinoamericano, no como una evangelización, sino una posibilidad de pensar el centro desde fuera; o de pensar la mundialización como pluricentralidad planetaria?

Nos parece que una revisión crítica de procesos históricos singulares latinoamericanos lograría generar secciones complejas de entendimiento, liberada del ingente esfuerzo, casi inabarcable, de pautar la diversidad continental que alberga. Aplicarse la crítica implica aceptar la posibilidad de un cambio de visión de las cosas que parecían inamovibles. Pero tal empresa es de enorme envergadura y estas preguntas no pueden ser responsabilidad única de los autores que conforman este número.

Tales autores han sido invitados específicamente por sus aperturas en las indagaciones en este sentido y, en conjunto, la visión resultante de lo que aquí publicamos ya es un diagnóstico plausible aun en el desbordante reto que como editores les hemos formulado. La elección ha conllevado una "plurivisión integradora", por usar un aforismo ilustrativo. La transversalidad con la que el matemático y filósofo Fernando Zalamea configura su pensamiento desde hace décadas, con libros centrados sobre una figuración del Sur Americano, alcanzan con su artículo "La arquitectura penumbrosa de América y el Sur bajo la perspectiva de los topos de Grothendieck", un grado de madurez y sensibilidad que se expresa con una claridad deslumbrante y, asumiendo nuestras hipótesis, las sitúa en lo que él llama un fabuloso espacio de trasiego y contradicciones en la vida del conti- nente. El desplazamiento que su pensar provoca, en la misma línea que hemos querido grafitar con el artista Alexandre Orion, recorriendo y matizando como voz en off cada texto, apunta a una originalidad por trasmutación -como el mismo Zalamea diría- de los reconocimientos evidentes, a partir de generar simbiosis con la matemática, la literatura, el arte y la filosofía. Incluso desde un fino análisis de "todo tipo de formas de vacío capturadas con el prefijo DES", en la arquitectura. Su texto sobrevuela las tesis que expuso en su "America una Trama Integral. Transversalidad, Bordes y Abismos en la Cultura Americana, Siglos XIX y XX" y merecen tanto ese libro como este artículo un ulterior estudio minucioso por los lectores de Astrágalo, dado que facultará encuentros fértiles para investigaciones venideras. Al extraer del prolífico matemático Grothendieck -de quien $\mathrm{Za}$ lamea es una autoridad mundial y es obligado referenciar aquí su seminal y descomunal libro "Grothendieck, una guia a la obra matemática y filosófica" -, la doble iteración que aploma el paso de lo en-sí a lo en-múltiple, entronca con las lógicas multivalentes que queríamos hallar para este número de Astrágalo.

Ello da el paso franco necesario al siguiente texto, "Habitabilidad y Diseño: La interdependencia radical y la terraformatividad de las ciudades" del profesor en Antropología Arturo Escobar. El profesor de la Universidad de Carolina del Norte-Chapel Hill y del doctorado en Ciencias Ambientales en la Universidad del Valle en Cali, Colombia, plantea un reencuentro con la Tierra. Lo hace desde su pensar bilingüe, desde el que ofrece el término "Re-earthing", que hemos traducido en un debate interno con múltiples actores de enorme riqueza, como, tal vez no finalmente, "terraformar". El trabajo rea- 
lizado por la comisión científica de esta revista ha sido de una enorme intensidad, con una grandísima recompensa en aprendizajes. Por ello hay una recensión del libro de Escobar "Otro Diseño para otra Sociedad. Autonomía y Diseño. La realización de lo comunal" y varias notas explicativas en el propio artículo. La convergencia de criterios con el último trabajo de Bruno Latour “¿Dónde Aterrizar?” es crucial para entender las miopes atenciones prestadas a problemas políticos globales que no lo son, de ninguna manera, en comparación. Escobar, como Latour, -diríamos- ya no cree que haya un ideal compartido para eso que se sigue llamando "Occidente" y que la nueva universalidad no puede ser otra que el darnos cuenta de que el suelo está desintegrándose. La antigua dicotomía moderna que daba a elegir sin elección entre aferrarse al suelo o mundializarse, está llegando a su fin, a su Fisterra. Escobar trabaja en su texto sobre las formas de habitabilidad y urbanismo desapegadas de la Tierra -no terraformadas, dirá-, determinantes para la crisis civilizatoria del sistema heteropatriarcal capitalista moderno/colonial mundial y para su expresión más importante, la ciudad. La perspicaz demostración de la capacidad argumental por el Pluriverso en Escobar, comparte escenario -colombiano-y rigor expositivo en el artículo del geógrafo político de la Florida International University, Ulrich Oslender. La ejemplificación que hace propias las tesis de puesta a tierra con el estudio titulado "Voces desde la marginalidad acuática: caminos fluviales hacia una arquitectura del pluriverso" responde con versatilidad a esa posibilidad de posicionamientos que queríamos encontrar para de ellas aprender previamente a un punto de no retorno, del que por cierto parece que ya estamos en él.
Esas contramedidas ilustrativas de lo cotidiano indiferente, en el artículo de Oslender, se envuelven en los trazos insinuados de acción arquitectónica en dos textos emparentados, el del decano de la facultad de arquitectura de Talca, en Chile, Juan Román, y el del arquitecto y profesor de Proyectos Arquitectónicos en la Escuela de Arquitectura de Sevilla José López-Canti, enseñando lo aprendido en y por Talca como escuela. De lo mundializado por lo singular, a través de experiencias y sensibilidades no regladas. Tal alteridad por la ausencia de pretensiones al uso se muestra en los títulos elegidos. El del profesor sevillano, “...boca arriba con los ojos cerrados entre las hogueras" es más excitación nerviosa que rigor inexpresivo, y la ausencia de todo revestimiento antepuesto se percibe cuando al propio Román no le interesó siquiera colocar alguno. "Sin título" es cosa del equipo editorial, connotado -así lo creemos- por su carácter de resistencia y mayor cercanía a una posibilidad de cambio de mentalidad, o metanoética, como hemos definido más arriba. Aquí no encontramos ni tácticas ni estrategias, sino un tercero que se incluye entre la marginalidad y la globalidad, aspirando a ser, meramente, que es mucho más que aparentar ser para entrar en el capítulo añadido a un blockbuster book. Si usamos la mercadotecnia cultural en la ironía de mantener un término en el idioma de los monopolios, es para levantar acta de invalidez en el uso de los tropos lingüísticos. Ya no son tropa para resistir. Y el acta en nuestro número la levanta el tándem de geógrafo y politólogo, César Simoni Santos e Itaquê Santana Barbosa. En su artículo, técnico en su despliegue, sensible en lo que descubre, "Dispositivos y flujos financieros en el paisaje de la edificación brasileña, aquello que buscábamos 
del diferencial arquitectónico en Brasil torna a la propia Arquitectura -con mayúscula-, por su aparataje financiero complejo, representativa de una lógica mundializada y hegemónica de producción del espacio urbano y vergonzosamente cómplice de los males de la ciudad.

Cierra este número una de esas aproximaciones que intuíamos necesarias generando secciones a modo de revisión crítica de procesos históricos singulares latinoamericanos, con la idea de poder lanzar desde este germen nuevos números que consigan mapear con precisión lo que iniciamos con el número 24 y ahora con este 25. El artículo "Diálogos del Sur, entre la arquitectura y el arte: reflexiones de la historia de una amistad en la trayectoria de Jorge Oteiza y Javier Saenz de Oiza" de la profesora de la Montfort-Leicester University, Alona Martínez Pérez, asume el reto y reclama otras futuras voces a partir de la tensión por terceridad que suscita el recordar al Laocoonte.

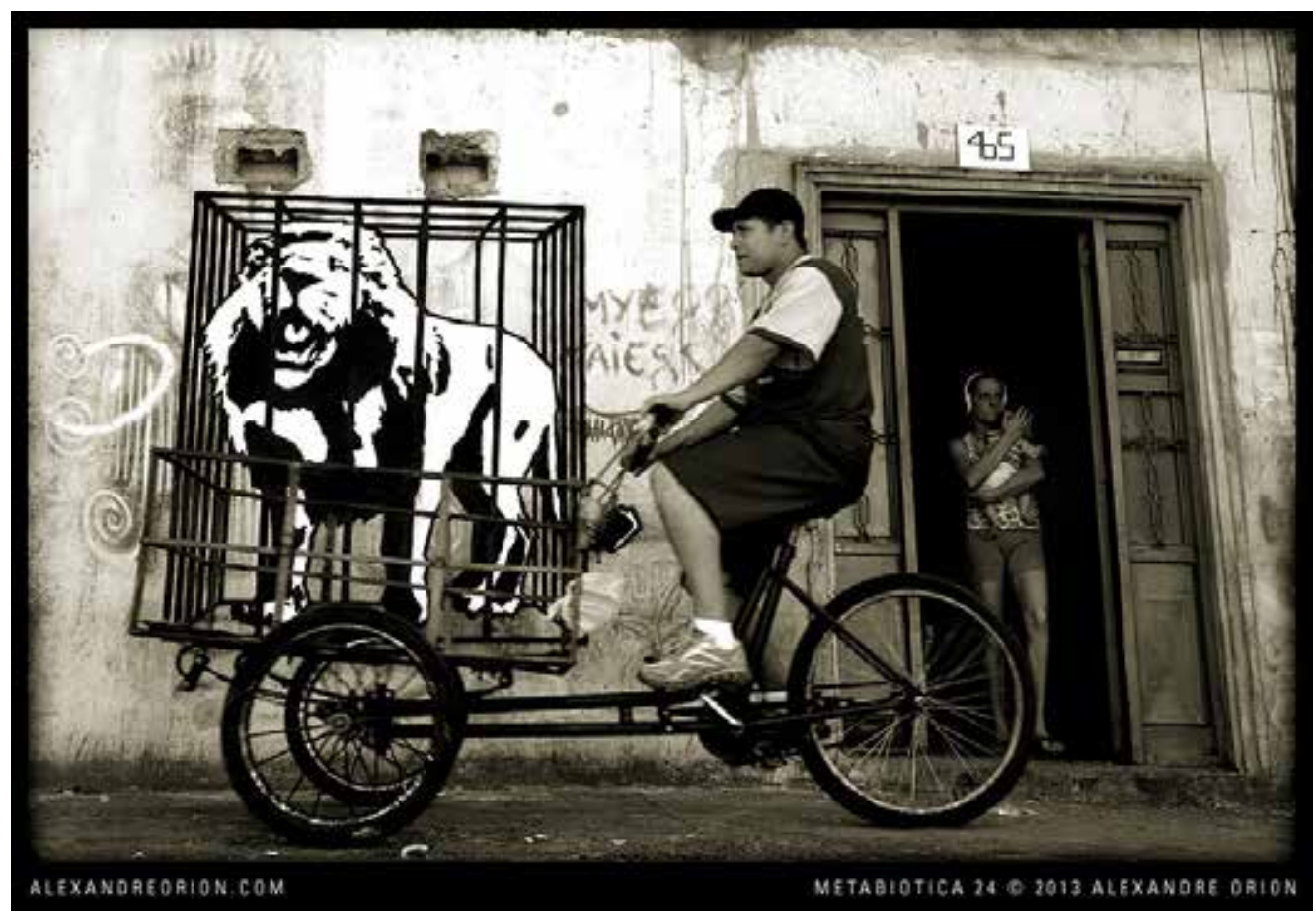

Metabiótica 24. 2013. Intervenção urbana seguida de registro fotográfico 